\title{
Parameter estimation of squirrel-cage motors with parasitic torques in the torque-slip curve
}

\author{
LI. Monjo, F. Córcoles and J. Pedra \\ Department of Electrical Engineering, ETSEIB-UPC, Av. Diagonal 647, Barcelona 08028, Spain. \\ E-mails: Iluis.monjo@upc.edu, corcoles@ee.upc.edu, pedra@ee.upc.edu
}

\begin{abstract}
This paper studies parasitic torques in steady-state torque-slip curves of squirrel-cage induction motors. The curves of nine motors (small, medium and large size units), three of which were measured in the range $s=2$ to $s=0$, are analyzed. The torque-slip curves of eight of these nine motors differ significantly from the smooth curves predicted by the classical single- and double-cage models: a torque dip at large slips in the motoring regime and a noticeable torque increase in the braking regime occur. As parasitic torques have been traditionally associated with space harmonics, two single-cage chain models (which consider the space harmonics) are tested to fit the measured torque and current of the three measured motors: one neglects the skin effect, leading to the wrong torque prediction while the other (the classical chain model in the literature) considers the skin effect, leading to an accurate torque prediction.
\end{abstract}

\section{Introduction}

Since the squirrel-cage induction motor became the most common industrial load, manufacturers have accumulated large amounts of data on torque- and current-slip curves.

Generally, measured curves can be approximated by the classical single- and double-cage induction machine models. However, a considerable number of motors have torque irregularities (also called parasitic torques) near zero speed in the torque-slip curve [1][2]. Table 1 contains manufacturer data of the nine motors considered in this paper. The parasitic torques are illustrated in the small size motor curves of Fig. 1 (laboratory measurements of motors \#1, \#2 and \#3 made by the authors) and in the medium size motor curves of Fig. 2 (manufacturer measurements of motors \#4, \#5 and \#6). More evidence of torque irregularities can be found using software tools provided by some manufacturers [3][4]. These tools plot or provide data about torque- and current-slip curves of their motors, where torque irregularities can be easily detected for some motors. For instance, Fig. 3 shows the curves of motor \#7 (obtained from [3]), where parasitic torques are evident. Another example can be found for 
Table 1 Manufacturer data of squirrel-cage induction motors

\begin{tabular}{ccccccccccc}
\hline \hline Motor & $P_{\mathrm{N}}(\mathrm{kW})$ & $U_{\mathrm{N}}(\mathrm{V})$ & $f_{\mathrm{N}}(\mathrm{Hz})$ & $P F_{\mathrm{N}}$ & $\omega_{\mathrm{N}}(\mathrm{r} / \mathrm{min})$ & $\eta_{\mathrm{N}}(\%)$ & $T_{\mathrm{MAX}} / T_{\mathrm{N}}$ & $T_{\mathrm{ST}} / T_{\mathrm{N}}$ & $T_{\mathrm{MIN}} / T_{\mathrm{N}}$ & $I_{\mathrm{ST}} / I_{\mathrm{N}}$ \\
\hline$\# 1$ & 1.5 & 400 & 50 & 0.69 & 950 & 79.1 & 2.3 & 1.7 & 1.5 & 3.9 \\
$\# 2$ & 4 & 400 & 50 & 0.80 & 1430 & 86.0 & 2.6 & 2.3 & 1.4 & 6.3 \\
$\# 3$ & 4 & 400 & 50 & 0.75 & 1445 & 86.7 & 3.4 & 3.1 & 2.5 & 7.1 \\
$\# 4$ & 15 & 400 & 50 & 0.81 & 985 & 91.0 & 2.8 & 2.1 & 1.5 & 6.6 \\
$\# 5$ & 30 & 400 & 50 & 0.85 & 1475 & 92.0 & 2.2 & 2.4 & 1.7 & 5.0 \\
$\# 6$ & 45 & 400 & 50 & 0.89 & 2960 & 94.1 & 2.8 & 3.0 & 2.2 & 7.1 \\
$\# 7$ & 88 & 400 & 50 & 0.84 & 1479 & 94.7 & 3.4 & 3.2 & 2.0 & 7.6 \\
$\# 8$ & 250 & 400 & 50 & 0.86 & 1490 & 97.0 & 2.4 & 1.4 & 1.1 & 8.0 \\
$\# 9$ & 500 & 400 & 50 & 0.88 & 1488 & 95.8 & 2.4 & 2.1 & 1.8 & 6.5 \\
\hline \hline
\end{tabular}

the large size motors \#8 and \#9 (obtained from [4]), where the minimum torque is lower than the starting torque ( $T_{\mathrm{MIN}} / T_{\mathrm{ST}}$ is 0.78 and 0.86 , respectively, Table 1 ). This is indicative of a torque-slip curve similar to that of the motors in Fig. 1, Fig. 2 and Fig. 3.

Fig. 1 and Fig. 2 also show that the classical double-cage model parameters (solid lines) estimated from the measurements clearly fail to predict the data measured for five of the six motors, and that the classical singlecage model parameters (broken lines) provide an even worse prediction for the six motors.

The notable differences between theoretical and experimental torque/speed curves have been pointed out in the classical literature [1][5]-[8], and are generally associated with space harmonics. A thorough analysis of this outdated topic reveals that a combination of effects is responsible for the parasitic torques: space harmonics due to slot openings, leakage and main flux path saturation, skin effect and rotor eccentricity, among others [1][5][8][14]. A priori, the quality of the air-gap field should depend on the motor size and design. However, there are no
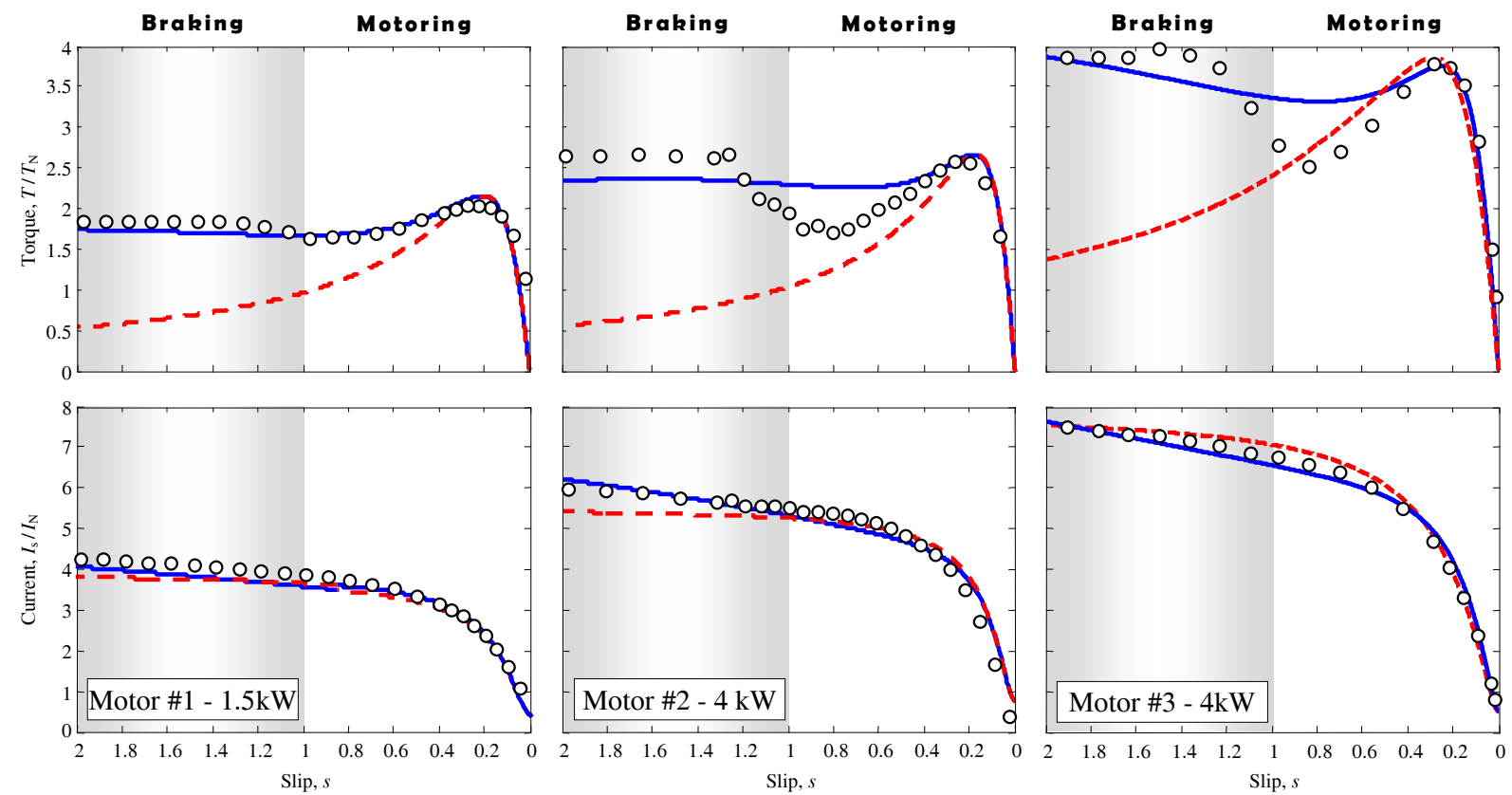

Fig. 1 Measured torque-and current-slip data (circles) for the three tested small size motors. Curves estimated with the classical singleand double-cage models (broken and solid lines, respectively) are also drawn. Note that the measured range has been extended to the braking regime (shaded area). 

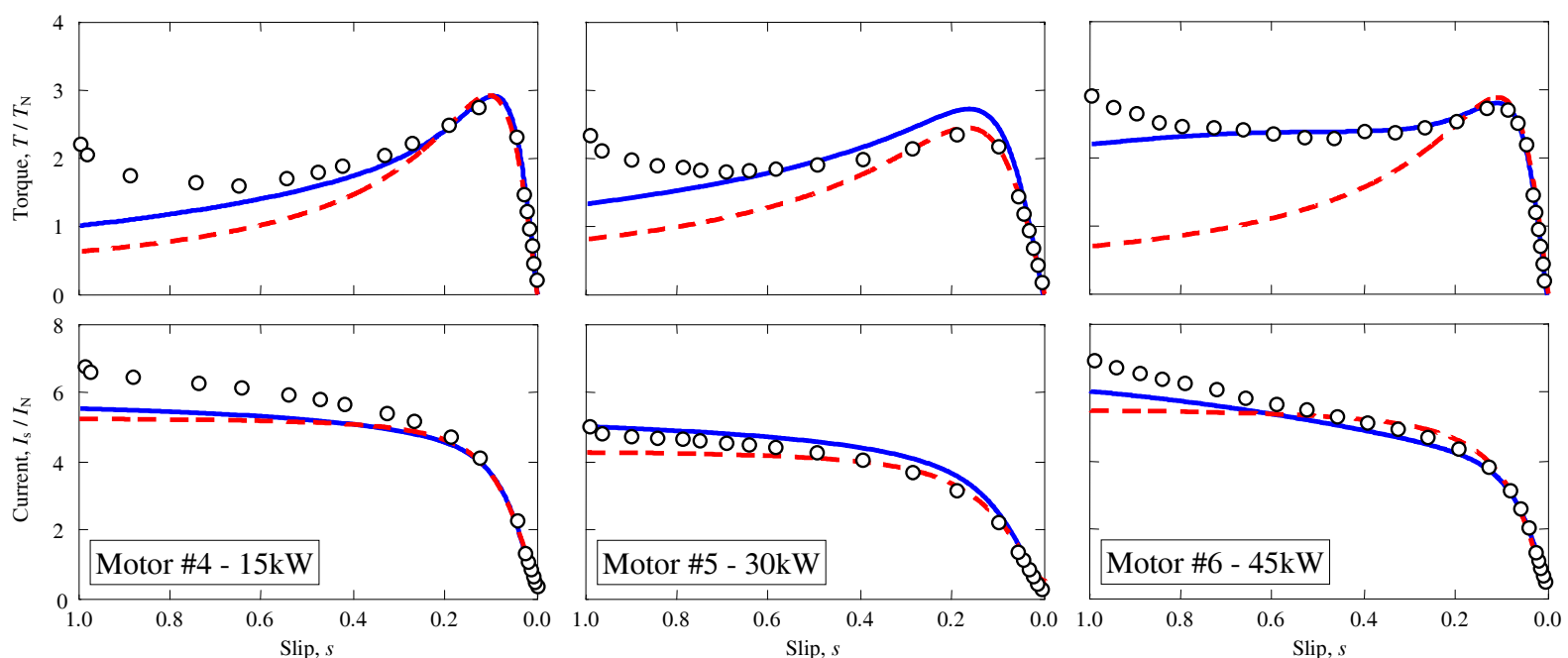

Fig. 2 Measured torque-and current-slip data (circles) for the three tested medium size motors. Curves estimated with the classical singleand double-cage models (broken and solid lines, respectively) are also drawn.

significant differences between the torque curve shapes of the low and medium size motors of Fig. 1, Fig. 2 and Fig. 3 and those that can be guessed for the large size motors \#8 and \#9 in Table 1.

The available models to study squirrel-cage motors in the presence of space harmonic effects can be categorized into three groups:

- Accurate electromagnetic models, e.g., finite-element method models. These models are usually chosen in
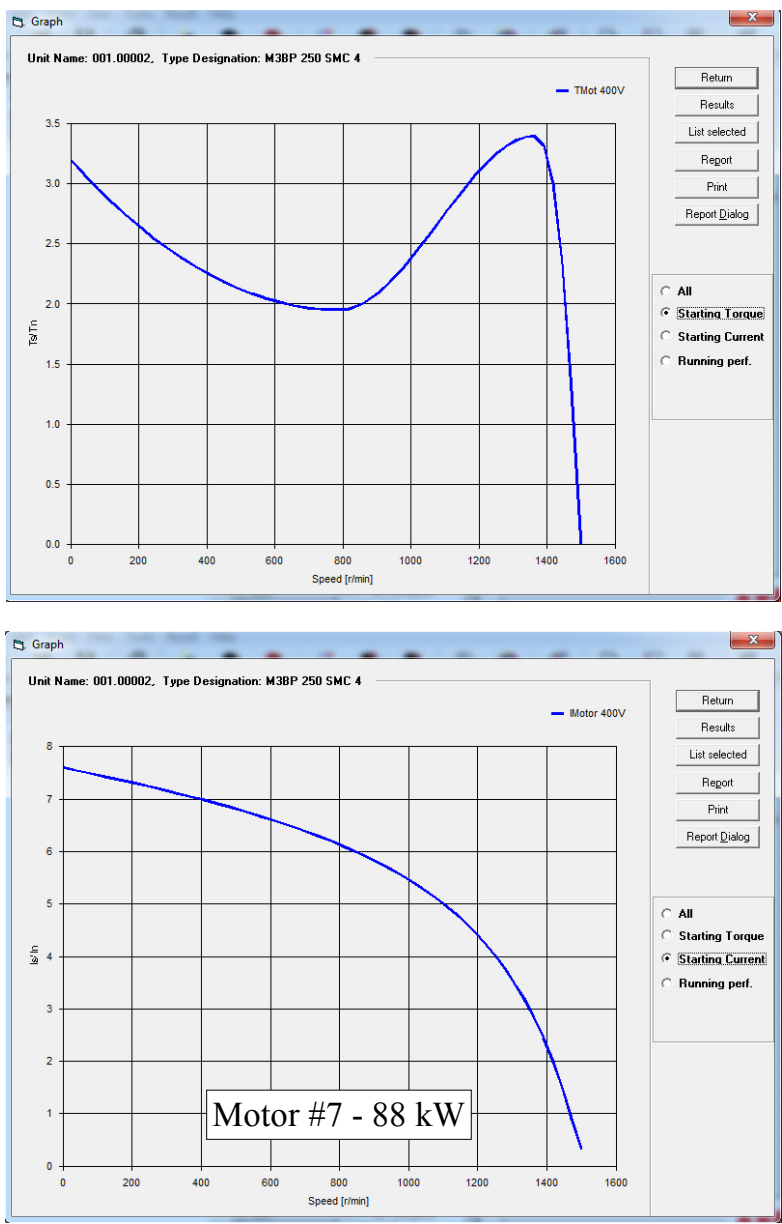

Fig. 3 Torque-and current-slip curves provided by the manufacturer software for motor \#7 [3]. 
the stage design and require the use of manufacturer confidential data.

- Models which include not only the number of stator turns and rotor bars in slots (winding harmonics), but also air-gap permeance variation (slot harmonics) [1][8]-[14]. The complexity of such models is outside the scope of this paper.

- Simplistic steady-state equivalent circuits, i.e., the chain models in Fig. 5c-d. These models are numerically efficient and provide accurate steady-state torque- and current-slip curves.

This paper focuses on the third type of models. An accurate prediction of their torque and current is required in the next practical cases:

- Calculation of motor starting time, mainly when constant power loads are driven (loads with high starting torque requirement).

- Prediction of stator current consumption and rotor speed stability in case of a large speed drop due to a voltage sag [15].

- Use of aggregated motor models for power system studies.

In this paper, the steady-state torque and current of motors \#1, \#2 and \#3 operating in the braking and motoring regimes are measured, and a set of parameters for the steady-state equivalent circuit (which must be valid for both regimes) is searched for. Two sets of estimated parameters failed in the torque-slip curve prediction. In the first, the classical single- and double-cage models were used whereas in the second, the singlecage chain model, which considers the space harmonics but neglects the skin effect, was employed. Finally, the classical single-cage chain model (which includes both space harmonics and skin effect, and was proposed in the early 60's [5]-[7][16]) successfully predicts the measured data.

Despite the great number of references to the classical single-cage chain model [1][2][5]-[8][14], few studies in the literature fit this model to measurements, i.e., its ability to predict measured machine behaviour in the presence of space harmonic effects has not been evaluated.

\section{Torque irregularities background}

Despite the good agreement between measured torques and currents and smooth curves predicted by the classical single- and double-cage models, the torque-slip curve of some squirrel-cage motors has irregularities (i.e., torque dips and cusps at large slips) which cannot be predicted by these models [1]. This is the case of motors \#2 to \#9.

The torque-slip curve of the classical models is smooth because it is assumed that stator and rotor windings are sinusoidally distributed. As a consequence, the air-gap magnetomotive force (mmf) and flux density generated by a winding are also sinusoidally distributed. However, because of the (1) non-sinusoidal winding distribution, (2) slotting and (3) machine saturation, the resulting air-gap flux density becomes a non-sinusoidal function. This is translated into harmonic torques (also called parasitic torques), which may be of considerable amplitude [1]. It was observed that, for some stator and rotor slot combinations, harmonic torques could seriously impair (or even prevent) motor start up. This is known as crawling. Indeed, pronounced irregularities at large slips and in the braking regime (also known as hooks) were reported experimentally [5]-[8]. Some authors tried to explain this behaviour analytically and make rules to prevent its occurrence [1][8]. 


\section{Laboratory measurements}

The squirrel-cage motors \#1, \#2 and \#3 were tested by the authors in the laboratory whereas motors \#4, \#5 and \#6 were tested by the manufacturer. The tests measured the torque and the stator current at different steady-state operating points (at different speeds). To collect more information, the measured range also included the braking regime (i.e., torque and current were measured from $s=2$ to $\mathrm{s}=0$ ) for motors \#1 to \#3.

Motors \#1, \#2 and \#3 were tested at a reduced voltage of $0.82 \cdot U_{\mathrm{N}}=328 \mathrm{~V}$ due to source limitations while motors \#4, \#5 and \#6 were tested at $0.57 \cdot U_{\mathrm{N}}=230 \mathrm{~V}$. The torque and current measured at a reduced voltage are prorated to the rated voltage to make them comparable:

$$
\begin{aligned}
& T_{\text {prorated }}=T_{\text {measured }}\left(\frac{U_{\mathrm{N}}}{U_{\text {measured }}}\right)^{2} \\
& I_{\text {s prorated }}=I_{\mathrm{s} \text { measured }} \frac{U_{\mathrm{N}}}{U_{\text {measured }}} .
\end{aligned}
$$

The experimental measurements are represented by circles in Fig. 1 and Fig. 2. Strong torque irregularities which may be the cause of disagreement between theoretical and experimental curves, especially if the classical single-cage model is used in the braking regime of Fig. 1, can be observed. The effect varies for the different motors; that is, while in motor \#1 torque irregularities are practically inexistent, the remaining five motors exhibit a torque dip at large slips (in the motoring regime). Furthermore, motors \#2 and \#3 show a pronounced torque increase in the braking regime.

Despite these irregularities, the current-slip curves are very smooth in the six cases. The smooth torque curve of motor \#1 makes it possible to fit the measurements by the classical models, as seen in the next section. On the other hand, the torque curves of the remaining five motors probably require a more complete machine model. Regarding the origin of the torque irregularities in these five motors, the space harmonics are a good candidate after examination of the almost pathological torque curves measured in [6][8], where abrupt hooks were caused by the space harmonics due to specific stator and rotor slot combinations. Machine saturation could be another cause for these irregularities, but this possibility is ruled out in the next subsection.

\subsection{Discarding machine saturation}

To discard saturation as the origin of the irregularities in Fig. 1, Fig. 2 and Fig. 3, the following laboratory test was made on motor \#3. The motor was fed at four voltage levels in the whole speed range in order to obtain the corresponding torque- speed curves. Each voltage level includes the saturation effect at all operating points, including large slip ones, where the current is several times greater than the nominal [17]. By making different tests at a) 0.82 times the nominal voltage $U_{\mathrm{N}}$, which represents the normal saturation level, b) 0.61 and 0.41 times the nominal voltage, which represent medium saturation levels, and c) 0.20 times the nominal voltage, which characterizes the unsaturated machine, the curves with the (prorated) measurements for motor \#3 are obtained and represented in Fig. 4.

The following conclusions can be drawn:

- According to [17], the effect of main flux saturation on the torque-slip curves is negligible if the speed is far from synchronism.

- Moreover, the differences in torque values for the different voltage levels can be attributed to leakage 

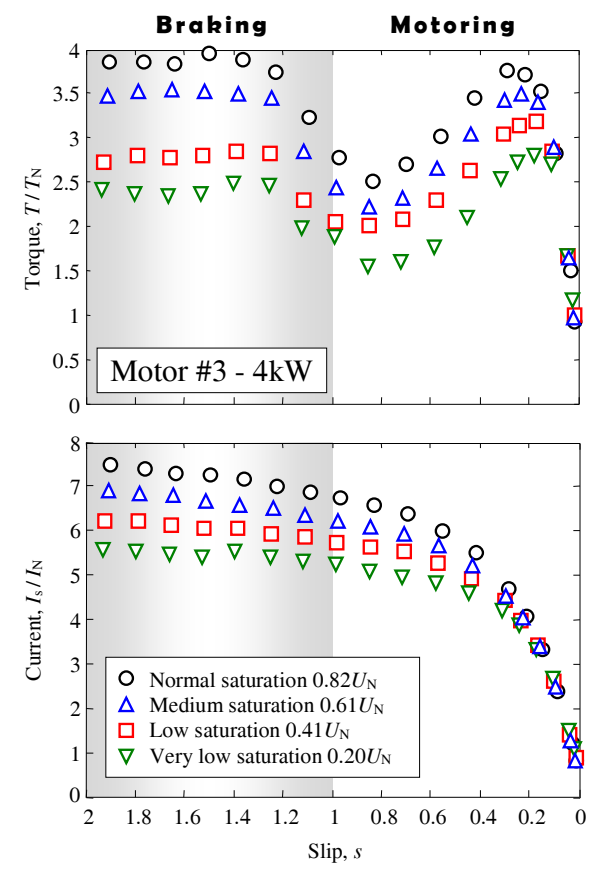

Fig. 4 Measured torque- and current-slip curves for motor \#3 at different voltage levels.

inductance saturation [17], which depends on the current consumption. Note that the current is several times greater than the nominal at most operating points.

- Although the curves are slightly different at the different saturation levels, they have a similar shape.

In summary, saturation should not be considered the sole origin of the measured irregularities.

\subsection{Measured stator current harmonics}

Instantaneous stator currents measured in the tests of Fig. 1 were almost sinusoidal in all cases. It is worth noting that these measurements are in full agreement with the results in [14], where detailed simulations show that, unlike their obvious influence on the torque, the impact of space harmonics on stator currents is almost negligible. The space harmonic models used in this paper (chain models in Fig. 5c-d) are based on the assumption that the stator currents are purely sinusoidal.

\section{Models for predicting the measured behaviour}

Once motor saturation is ruled out, an attempt was made to fit the measured machine behaviour with the three types of models in Sections 5, 6 and 7:

(1) the classical single- and double-cage models in Fig. 5a-b, which consider sinusoidal air-gap flux density distribution;

(2) the single-cage chain model in Fig. 5c, which considers space harmonics due to non-sinusoidally distributed windings and uniform air-gap but neglects the skin effect, and

(3) the single-cage chain model in Fig. 5d, which takes into account both space harmonics and skin effect.

The chain models are based on the common assumption that the squirrel-cage rotor reacts to all harmonic fluxes in the same way as to the fundamental, thus leading to a parasitic torque-slip curve for each harmonic $[1][6]$. 


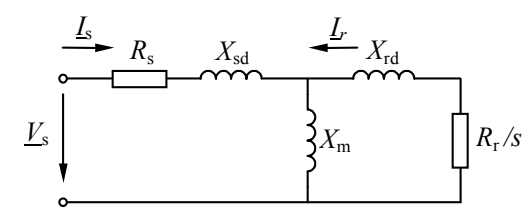

(a)

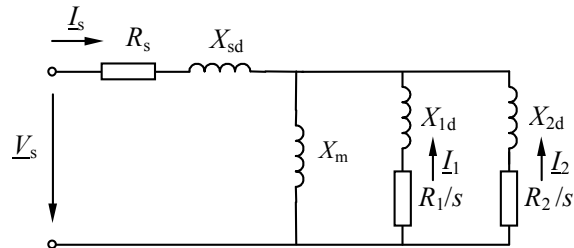

(b)

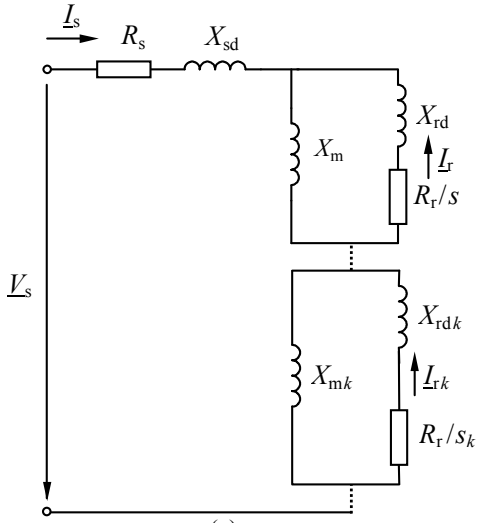

(c)

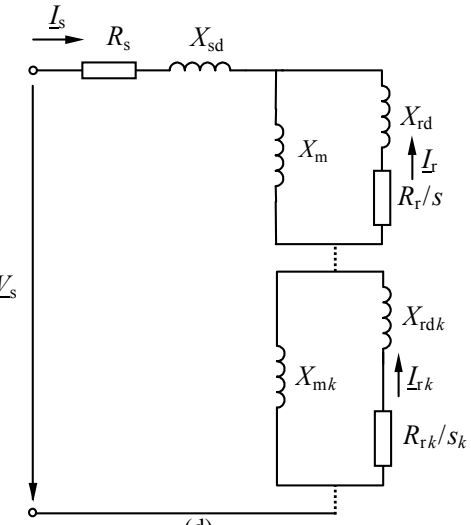

(d)

Fig. 5 Classical models for the squirrel-cage motor: (a) single-cage model, (b) double-cage model. Space harmonic models for the squirrel-cage motor: (c) single-cage chain model without skin effect, (d) single-cage chain model with skin effect.

\section{Classical single- and double-cage models}

Fig. 5a-b shows the equivalent circuits for the classical single- and double-cage induction machine models. Their torque is calculated with the following equations:

$$
T(s)=\frac{3 p}{\omega_{\mathrm{s}}}\left(\frac{R_{\mathrm{r}}}{s} I_{\mathrm{r}}^{2}\right) \quad, \quad T(s)=\frac{3 p}{\omega_{\mathrm{s}}}\left(\frac{R_{1}}{s} I_{1}^{2}+\frac{R_{2}}{s} I_{2}^{2}\right)
$$

where $s=\frac{\omega_{\mathrm{s}}-p \omega_{\mathrm{m}}}{\omega_{\mathrm{s}}}$ is the slip at the fundamental frequency and $p$ is the number of pole pairs.

\subsection{Parameter estimation}

As the stator resistance $R_{\mathrm{S}}$ was measured off-line, only three functional relationships can be estimated between the remaining four unknown electrical parameters of the single-cage model in Fig. 5a [18]. As a solution, the restriction $X_{\mathrm{sd}}=X_{\mathrm{rd}}$ is arbitrarily chosen in this study. The estimation procedure is based on the following data and unknowns:

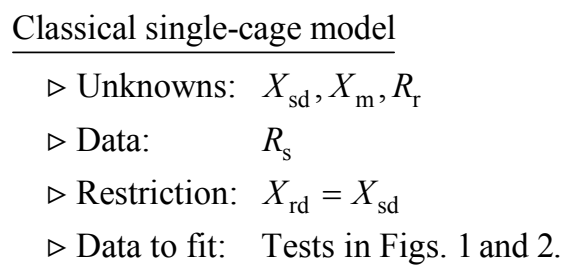

Regarding the double-cage model in Fig. 5b, it has six unknown electrical parameters as $R_{\mathrm{s}}$ has been measured. Since only five functional relationships between these parameters are independent [18], the restriction $X_{\mathrm{sd}}=X_{2 \mathrm{~d}}$ is arbitrarily chosen in this paper. The estimation procedure is based on the following data and unknowns:

$$
\begin{aligned}
& \text { Classical double-cage model } \\
& \triangleright \text { Unknowns: } X_{\mathrm{sd}}, X_{\mathrm{m}}, R_{1}, X_{1 \mathrm{~d}}, R_{2} \\
& \triangleright \text { Data: } \quad R_{\mathrm{s}} \\
& \triangleright \text { Restriction: } X_{2 \mathrm{~d}}=X_{\text {sd }} \\
& \triangleright \text { Data to fit: Tests in Figs. } 1 \text { and } 2 \text {. }
\end{aligned}
$$


Table 2 Single- and double-cage model estimated parameters in pu $\left(S_{\mathrm{B}}=P_{\mathrm{N}}, U_{\mathrm{B}}=U_{\mathrm{N}}, Z_{\mathrm{B}}=U_{\mathrm{B}}{ }^{2} / S_{\mathrm{B}}\right)$

\begin{tabular}{l|ccccc|cccccccccc}
\hline & \multicolumn{3}{|c}{ Single-cage } & \multicolumn{1}{c}{ Double-cage } \\
& $r_{\mathrm{s}}$ & $x_{\mathrm{sd}}$ & $x_{\mathrm{m}}$ & $r_{\mathrm{r}}$ & $x_{\mathrm{rd}}$ & $r_{\mathrm{s}}$ & $x_{\mathrm{sd}}$ & $x_{\mathrm{m}}$ & $r_{1}$ & $x_{1 \mathrm{~d}}$ & $r_{2}$ & $x_{2 \mathrm{~d}}$ \\
Motor \#1 & 0.0422 & 0.0749 & 1.0617 & 0.0313 & 0.0749 & 0.0422 & 0.0595 & 1.0771 & 0.0371 & 0.1236 & 0.2430 & 0.0595 \\
Motor \#2 & 0.0350 & 0.0612 & 1.0328 & 0.0218 & 0.0612 & 0.0350 & 0.0409 & 1.0532 & 0.0253 & 0.1060 & 0.2153 & 0.0409 \\
Motor \#3 & 0.0244 & 0.0402 & 1.2767 & 0.0253 & 0.0402 & 0.0244 & 0.0244 & 0.0250 & 1.2103 & 0.0241 & 0.0836 & 0.1781 \\
Motor \#4 & 0.0422 & 0.0749 & 1.0617 & 0.0313 & 0.0749 & 0.0422 & 0.0595 & 1.0771 & 0.0371 & 0.1236 & 0.2430 & 0.0595 \\
Motor \#5 & 0.0350 & 0.0612 & 1.0328 & 0.0218 & 0.0612 & 0.0350 & 0.0409 & 1.0532 & 0.0253 & 0.1060 & 0.2153 & 0.0409 \\
Motor \#6 & 0.0244 & 0.0402 & 1.2767 & 0.0253 & 0.0402 & 0.0244 & 0.0244 & 0.0250 & 1.2103 & 0.0241 & 0.0836 & 0.1781 \\
\hline \hline
\end{tabular}

\subsection{Least-squares algorithm for parameter estimation}

In this paper, the model parameters are estimated with a MATLAB built-in function for least-squares fit [19]. The errors between estimated and measured data are given in values relative to the measured values:

$$
\varepsilon_{\mathrm{x} i}=\left|\frac{x_{i \text { estimated }}-x_{i \text { measured }}}{x_{i \text { measured }}}\right| .
$$

The error function to be optimized is a column vector $[\mathbf{F}]$ composed of the following scalar error functions, where the weight given to each point $\left(w_{i}\right)$ can be modified if needed:

$$
\begin{aligned}
{[\mathbf{F}]=\left[\begin{array}{l}
F_{1} \\
F_{2}
\end{array}\right] \quad \text { where: } F_{1} } & =\frac{1}{N} \sum_{i=1}^{N} w_{i} \varepsilon_{\text {torque } i} \\
F_{2} & =\frac{1}{N} \sum_{i=1}^{N} w_{i} \varepsilon_{\text {current } i} \\
w_{i} & =1 .
\end{aligned}
$$

The least-squares algorithm minimizes the 2-norm residual error:

$$
\text { Residual error }(\%)=\|\mathbf{F}\|_{2}=100 \cdot\left(\sum_{i=1}^{2} F_{i}^{2}\right)^{1 / 2} \text {. }
$$

To avoid negative values of the estimated parameters, it is recommended to force all parameters to be always positive [18].

\subsection{Estimation results analysis}

The parameters estimated for the classical models of motors \#1 to \#6 are given in Table 2. The predicted torque- and current-slip curves are calculated from these parameters and plotted in Fig. 1 and Fig. 2 (single-cage: broken line; double-cage: solid line).

Analysis of both figures shows that the classical single-cage model cannot accurately predict the behaviour of any of the six motors.

The classical double-cage model can be considered adequate only for motor \#1 given that, although the torque-slip curve is very smooth and provides better results, it also fails to predict the torque of the remaining five motors.

It is worth noting that the torque predictions in the motoring regime (from $s=1$ to $s=0$ ) for motors \#2 and \#3 can lead to the wrong conclusion that the classical single-cage models are more accurate in such a speed range. 
This is erroneous as the classical double-cage models in Fig. 1 provide better predictions in the whole speed range (i.e., from $s=2$ to $s=0$ ).

Although motors \#7, \#8 and \#9 were not tested, the low values of the minimum torque compared to the starting torque $\left(T_{\mathrm{MIN}} / T_{\mathrm{ST}}\right)$ in Table 1 suggest that the classical single- and double-cage models would fail in the torque prediction

\section{Single-cage chain model without skin effect}

Fig. 5c illustrates the steady-state equivalent circuit for the three-phase induction machine with nonsinusoidally distributed windings and uniform air-gap. The model considers a single-cage for the rotor and neglects the skin effect. As can be seen, the circuit contains a rotor subcircuit for any considered space harmonic, resulting into a chain model. As the skin effect is neglected, the rotor resistance is identical for all subcircuits, and the leakage reactances $X_{\mathrm{rd} \mathrm{k}}$ are rigidly related to $X_{\mathrm{m}}, X_{\mathrm{m} \mathrm{k}}$ and $X_{\mathrm{rd}}$. Appendix 2 contains a detailed deduction of the model equations because no complete demonstration was found in the literature.

The authors tried to fit the model to the measurements of Fig. 1. As the adjustment was unsuccessful in all cases, it can be concluded that the model is unable to predict the measured squirrel-cage torque irregularities in Fig. 1. As a result, it seems apparent that the skin effect must be included in the space harmonic model.

\section{Single-cage chain model with skin effect}

Fig. $5 \mathrm{~d}$ shows the steady-state equivalent circuit for the three-phase induction machine which includes the space harmonics and the skin effect [1][2]. This model maintains the rotor subcircuit topology in Fig. 5c. However, the skin effect consideration results in variable rotor resistances and reactances $X_{\text {rd } \mathrm{k}}$ for any considered space harmonic. The model is also valid for non-uniform air-gap (slot harmonics).

In this model, the total and harmonic torques are calculated as follows:

$$
\begin{gathered}
T(s)=\sum_{k=1,5,7 \ldots} T_{k}(s)=\sum_{k=1,5,7 \ldots} \pm k \frac{3 p}{\omega_{\mathrm{s}}}\left(\frac{R_{\mathrm{r} k}}{s_{k}} I_{\mathrm{r} k}^{2}\right) \\
\text { being: } \quad s_{k}=\frac{\omega_{\mathrm{s}}-\left( \pm k p \omega_{\mathrm{m}}\right)}{\omega_{\mathrm{s}}}=1-( \pm k(1-s)) \\
(k=1,5,7,11 \ldots),
\end{gathered}
$$

where \pm must be interpreted as follows:

$\triangleright$ the positive sign is for the forward harmonics: the fundamental $(k=1)$ and the harmonics of order $k=7$, $13 \ldots$ (i.e., $k=6 n+1$, where $n=0,1,2 \ldots$ ).

$\triangleright$ the negative sign is for the backward harmonics: the harmonics of order $k=5,11 \ldots$ (i.e., $k=6 n+5$, where $n=0,1,2 \ldots)$.

\subsection{Parameter estimation}

The $5^{\text {th }}, 7^{\text {th }}$ and $11^{\text {th }}$ harmonics are chosen for curve fitting. It must be remembered that the $7^{\text {th }}$ harmonic flux travels forward (in the direction of the fundamental field) at a sub-synchronous speed of $\left(\omega_{\mathrm{s}} / p\right) / 7$ while the $5^{\text {th }}$ 
and $11^{\text {th }}$ travel backward at sub-synchronous speeds of $\left(\omega_{\mathrm{s}} / p\right) / 5$ and $\left(\omega_{\mathrm{s}} / p\right) / 11$. The estimation procedure is based on the following data and unknowns:

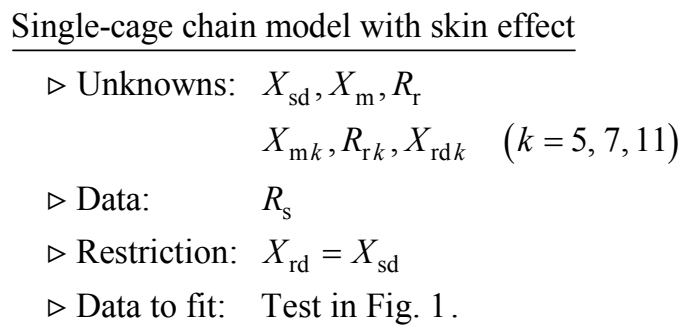

Note that the arbitrary restriction $X_{\mathrm{sd}}=X_{\text {rd }}$ is again imposed on the parameters related to the fundamental flux.

\subsection{Estimation results analysis}

he parameters estimated for motors \#1, \#2 and \#3 are given in Table 3. It is worth noting that, while the estimation for motors \#1 and \#3 was very straightforward, in the case of motor \#2 it was necessary to modify the weights given to the different points, $w_{i}$.

The predicted curves are calculated from the parameters of Table 3 and plotted in Fig. 6. This figure also contains the contribution of the harmonic torques, whose zero-crossing occurs at $s=1-( \pm 1 / k)=1+1 / 5$, $1-1 / 7,1+1 / 11$, as can be deduced from (8) by imposing $s_{k}=0$.

Note that the harmonic torque curves are not symmetrical about the horizontal axis, just like in the classical models in Fig. 5a-b (the torque-slip curve for motor operation is not identical to that for generator operation). This asymmetry is particularly apparent in the $7^{\text {th }}$ harmonic torques of the three motors because there is a significant torque increase in the braking regime whereas the impact at rated slip is low.

The fit obtained for motor \#1 in Fig. 6 is slightly better than that obtained with the classical double-cage model in Fig. 1. The fit for motors \#2 and \#3 is also excellent, as the estimated parameters accurately predict the pronounced torque irregularities.

Table 3 Single-cage chain model with skin effect: estimated parameters in pu $\left(S_{\mathrm{B}}=P_{\mathrm{N}}, U_{\mathrm{B}}=U_{\mathrm{N}}, Z_{\mathrm{B}}=U_{\mathrm{B}}{ }^{2} / S_{\mathrm{B}}\right)$

\begin{tabular}{|c|c|c|c|c|}
\hline & & Motor \#1 & Motor \#2 & Motor \#3 \\
\hline & $r_{\mathrm{s}}$ & 0.0422 & 0.0350 & 0.0244 \\
\hline & $x_{\mathrm{sd}}=x_{\mathrm{rd}}$ & 0.0597 & 0.3701 & 0.0257 \\
\hline & $x_{\mathrm{m}}$ & 0.9288 & 1.2104 & 1.4292 \\
\hline & $r_{\mathrm{r}}$ & 0.0364 & 0.0349 & 0.0256 \\
\hline \multirow{3}{*}{ in } & $x_{\mathrm{m}(5)}$ & 0.0012 & 0.0071 & 0.0102 \\
\hline & $r_{\mathrm{r}(5)}$ & 0.1781 & 0.1197 & 0.3015 \\
\hline & $x_{\operatorname{rd}(5)}$ & 0.1909 & 0.0009 & 0.0180 \\
\hline \multirow{3}{*}{ 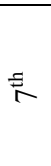 } & $x_{\mathrm{m}(7)}$ & 0.0075 & 0.0069 & 0.0053 \\
\hline & $r_{\mathrm{r}(7)}$ & 0.0784 & 0.1203 & 0.0698 \\
\hline & $x_{\text {rd (7) }}$ & 0.0024 & 0.0081 & 0.0039 \\
\hline \multirow{3}{*}{$\equiv$} & $x_{\mathrm{m}(11)}$ & 0.0001 & 0.0179 & 0.0102 \\
\hline & $r_{\mathrm{r}(11)}$ & 0.1101 & 0.4988 & 0.4302 \\
\hline & $x_{\mathrm{rd}(11)}$ & 0.1146 & 0.3202 & 0.0091 \\
\hline
\end{tabular}



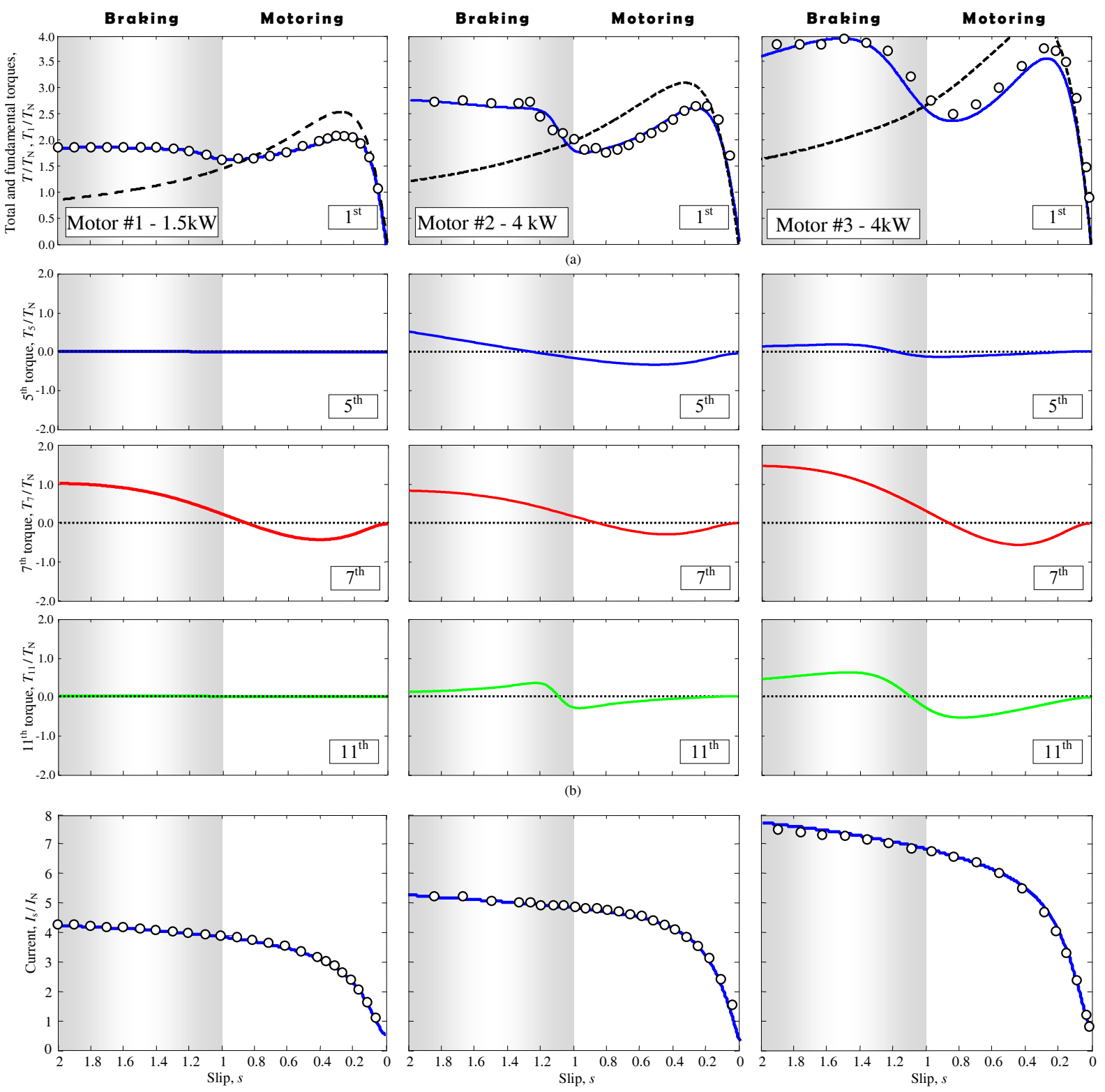

Fig. 6 Prediction of the single-cage chain model with skin effect for the three tested small size motors: (a) the total (solid line) and fundamental torques (broken line) (b) harmonic torques, and (c) total current.

The number of space harmonics is chosen a priori. Considering the results in Fig. 6 , the $5^{\text {th }}$ harmonic could be discarded a posteriori for motors \#1 and \#3, and the $11^{\text {th }}$ for motors \#1 and \#2 without significant loss of accuracy.

\section{Models summary}

The ability of each model to predict the torque curves measured in three motors is summarized in Table 4 . The classical single- and double-cage models and the single-cage chain model without skin effect are unable to simultaneously predict space harmonics and skin effect. On the contrary, the single-cage chain model which considers the skin effect provides accurate predictions. 


\begin{tabular}{|c|c|c|c|}
\hline & & Skin effect & Space harmonics \\
\hline Fig. 5a & Single-cage (classical model) & $\times$ & $x$ \\
\hline Fig. $5 b$ & Double-cage (classical model) & $\checkmark$ & $x$ \\
\hline Fig. $5 \mathrm{c}$ & Single-cage chain model without skin effect & $\times$ & $\checkmark$ \\
\hline Fig. $5 d$ & Single-cage chain model with skin effect & $\checkmark$ & $\checkmark$ \\
\hline
\end{tabular}

\section{Conclusions}

The paper shows the measured torque- and current-slip curves of six squirrel-cage induction motors. Five units exhibit apparent torque irregularities caused by space harmonics. For completeness, the measured range was extended to the braking regime $(s=2$ to $s=1)$ for three of the motors. The measured data are successfully fit by the following models: (1) the classical single- and double-cage models, (2) the single-cage chain model which considers space harmonics effects but neglects the skin effect, and (3) the single-cage chain model which takes into account both space harmonics and skin effects.

It is concluded that the smooth torque curves predicted by the classical models do not fit the measured curves when space harmonic effects are apparent. The single-cage chain model which neglects the skin effect also fails in the torque prediction despite considering space harmonics effects. On the contrary, the single-cage chain model which takes into account both space harmonics and skin effects exhibits excellent agreement with experimental data.

\section{Appendix 1: space harmonics}

The classical models assume that stator and rotor windings are sinusoidally distributed. As a consequence, the air-gap mmf of a winding is a perfectly sinusoidal waveform, i.e., the air-gap mmf of a winding supplied by current $i(t)$ can be expressed as a function of time and position angle $x$ as

$$
f(x, t)=F_{1} \cdot \cos (x-\alpha) \cdot i(t) \quad\left(F_{1}=\frac{2}{\pi} N \xi_{1}\right),
$$

where $\alpha$ is the winding magnetic axis of symmetry, and amplitude $F_{1}$ depends on the winding arrangement (number of turns $N$ and winding factor for the fundamental wave, $\xi_{1}$, i.e., distribution, pitch, and skew factors). The classical models also assume an unslotted machine having uniform air-gap of length $g$. Thus, the air-gap flux density $B$ is also sinusoidal:

$$
B(x, t)=\mu_{0} \cdot g^{-1} \cdot f(x, t)=\mu_{0} \cdot g^{-1} \cdot F_{1} \cdot \cos (x-\alpha) \cdot i(t),
$$

where $\mu_{0}$ is the permeability of free space.

In practice, the flux density contains harmonics produced by [1]: (1) concentration of mmf in a finite number of slots (winding harmonics), (2) non-uniform air-gap due to stator and rotor slot openings (slot harmonics), and (3) machine saturation. Then, the air-gap mmf and flux density can be expressed as [10]-[12]: 


$$
\begin{aligned}
& f(x, t)=\sum_{k=1,3,5} F_{k} \cdot \cos (k(x-\alpha)) \cdot i(t) \quad\left(F_{k}= \pm \frac{2}{\pi} \frac{N \xi_{k}}{k}\right) \\
& B(x, t)=\mu_{0} \cdot g^{-1}\left(x, p \theta_{\mathrm{m}}\right) \cdot \sum_{k=1,3,5} F_{k} \cdot \cos (k(x-\alpha)) \cdot i(t),
\end{aligned}
$$

where $k$ is the harmonic order (including the fundamental), and amplitude $F_{k}$ depends on the winding arrangement (number of turns $N$ and winding factor for harmonic $k, \xi_{k}$ ). The positive sign in $F_{k}$ is for the harmonics of order $k=2 n+1(n=0,1,2 \ldots)$, i.e., $k=1,5,11 \ldots$, while the negative sign is for the harmonics of order $k=2 n+3$, i.e., $k=3,7,9 \ldots$ The air-gap length is no longer a constant but depends on the position angle $x$ and the rotor mechanical angle $\theta_{\mathrm{m}}$ ( $p$ is the number of pole pairs). Only odd harmonics are considered in (12) because the winding arrangement is assumed to be symmetrical about its magnetic axis $\alpha$.

\subsection{Inductance calculation for non-sinusoidally distributed windings and uniform air-gap}

The mutual inductance $m_{\mathrm{ab}}$ of two windings $a$ and $b$ whose magnetic axes of symmetry are inclined at $\alpha_{\mathrm{a}}$ and $\alpha_{b}$ electrical degrees, respectively, is calculated by integration of the flux linkage of winding $a$, characterized by (12), with winding $b$. Assuming uniform air-gap, the resulting expression is [10]-[12]:

$$
\begin{aligned}
m_{\mathrm{ab}} & =\sum_{k=1,3,5} \mu_{\mathrm{o}} g^{-1} r b_{\mathrm{e}} \frac{4}{\pi} \frac{\left(N_{\mathrm{a}} \xi_{\mathrm{a} k}\right)\left(N_{\mathrm{b}} \xi_{\mathrm{b} k}\right)}{k^{2}} \cos \left(k\left(\alpha_{\mathrm{a}}-\alpha_{\mathrm{b}}\right)\right) \\
& =\sum_{k=1,3,5} m_{\mathrm{ab} k} \cos \left(k\left(\alpha_{\mathrm{a}}-\alpha_{\mathrm{b}}\right)\right),
\end{aligned}
$$

where $r$ is the average radius and $b_{\mathrm{e}}$ is the stack length. The calculation of the self-inductance of winding $a$ must also consider the leakage flux, i.e., the leakage flux inductance $l_{\mathrm{ad}}$ must be added to (13): $l_{\mathrm{a}}=m_{\mathrm{aa}}+l_{\mathrm{ad}}$.

\section{Appendix 2: single-cage chain model without skin effect}

In this appendix, a simplistic dynamic model in space vector variables for an induction machine with nonsinusoidally distributed windings, uniform air-gap and without skin effect is derived. By imposing electrical and mechanical steady-state, and assuming that a sinusoidal current source supplies the stator, the chain equivalent circuit in Fig. $5 \mathrm{c}$ is obtained. This circuit can be considered as a particular case of the more general chain model in Fig. 5d, which considers the space harmonics due to the skin effect and non-uniform air-gap. Because of its low computational burden, the model derived in this appendix can be used as a simulation tool to provide useful, qualitative dynamic and steady-state results.

\subsection{Model assumptions}

The following assumptions about a three-phase induction machine are made:

- Ideal magnetic circuit (negligible saturation and infinite relative magnetic permeability).

- Uniform air-gap.

- Three identical stator and rotor windings having constant parameters (due to skin effect on the rotor windings) and symmetrical arrangement about their magnetic axes (located at $\alpha, \alpha+2 \pi / 3$ and $\alpha-2 \pi / 3$ ).

- Constant leakage flux inductances.

The inductance calculation in (13) is simplified because the stator and rotor winding arrangements are 
identical $\left(\xi_{\mathrm{s} k}=\xi_{\mathrm{r} k}=\xi_{k}\right)$. Further simplification is obtained by reducing the rotor parameters to the stator $\left(N_{\mathrm{s}}=N_{\mathrm{r}}=N\right)$ :

$$
\begin{aligned}
m_{\mathrm{ab}} & =\sum_{k=1,3,5} \mu_{\mathrm{o}} g^{-1} r b_{\mathrm{e}} \frac{4}{\pi} \frac{\left(N \xi_{k}\right)^{2}}{k^{2}} \cos \left(k\left(\alpha_{\mathrm{a}}-\alpha_{\mathrm{b}}\right)\right) \\
& =\sum_{k=1,3,5} m_{k} \cos \left(k\left(\alpha_{\mathrm{a}}-\alpha_{\mathrm{b}}\right)\right) \quad\left(m_{k}=m_{1} \frac{\left(\xi_{k} / \xi_{1}\right)^{2}}{k^{2}}\right) .
\end{aligned}
$$

Note that concentrated windings (square-wave mmfs) lead to the largest space harmonic content. In this case, the maximum value for $m_{k}$ is obtained as $\xi_{k}=1$, resulting in $m_{k}=m_{1} / k^{2}$.

\subsection{Dynamic model equations in space vector variables}

The $a b c$ phase model for the induction machine is given by

$$
\begin{aligned}
& {[\mathbf{v}]=[\mathbf{R}][\mathbf{i}]+\frac{\mathrm{d}}{\mathrm{dt}}[\lambda] \quad[\lambda]=[\mathbf{M}(\theta)][\mathbf{i}]} \\
& \theta=p \theta_{\mathrm{m}}+\theta_{0} \\
& T(t)=\frac{1}{2}[\mathbf{i}]^{\mathrm{t}} \frac{\partial[\mathbf{M}(\theta)]}{\partial \theta_{\mathrm{m}}}[\mathbf{i}]=p \frac{1}{2}[\mathbf{i}]^{\mathrm{t}} \frac{\partial[\mathbf{M}(\theta)]}{\partial \theta}[\mathbf{i}],
\end{aligned}
$$

where $\theta$ is the rotor mechanical angle in electrical degrees and $\theta_{0}$ is its value at instant $t=0 \mathrm{~s}$. The inductance matrix is defined as

$$
[\mathbf{M}(\theta)]=\left[\begin{array}{ll}
\mathbf{M}_{\mathrm{s}} & \mathbf{M}_{\mathrm{sr}} \\
\mathbf{M}_{\mathrm{rs}} & \mathbf{M}_{\mathrm{r}}
\end{array}\right] .
$$

This matrix contains the winding inductances

$$
\begin{aligned}
& {\left[\mathbf{M}_{\mathrm{s}}(k)\right]=l_{\mathrm{sd}}\left[\begin{array}{lll}
1 & 0 & 0 \\
0 & 1 & 0 \\
0 & 0 & 1
\end{array}\right]+\sum_{k=1,3,5} m_{k}\left[\begin{array}{ccc}
1 & -1 / 2 & -1 / 2 \\
-1 / 2 & 1 & -1 / 2 \\
-1 / 2 & -1 / 2 & 1
\end{array}\right]} \\
& {\left[\mathbf{M}_{\mathrm{r}}(k)\right]=l_{\mathrm{rd}}\left[\begin{array}{lll}
1 & 0 & 0 \\
0 & 1 & 0 \\
0 & 0 & 1
\end{array}\right]+\sum_{k=1,3,5} m_{k}\left[\begin{array}{ccc}
1 & -1 / 2 & -1 / 2 \\
-1 / 2 & 1 & -1 / 2 \\
-1 / 2 & -1 / 2 & 1
\end{array}\right]} \\
& {\left[\mathbf{M}_{\mathrm{sr}}(k, \theta)\right]=\left[\mathbf{M}_{\mathrm{rs}}(k, \theta)\right]^{\mathrm{t}}} \\
& =\sum_{k=1,3,5} m_{k}\left[\begin{array}{ccc}
\cos (k \theta) & \cos \left(k\left(\theta+\frac{2 \pi}{3}\right)\right) & \cos \left(k\left(\theta-\frac{2 \pi}{3}\right)\right) \\
\cos \left(k\left(\theta-\frac{2 \pi}{3}\right)\right) & \cos (k \theta) & \cos \left(k\left(\theta+\frac{2 \pi}{3}\right)\right) \\
\cos \left(k\left(\theta+\frac{2 \pi}{3}\right)\right) & \cos \left(k\left(\theta-\frac{2 \pi}{3}\right)\right) & \cos (k \theta)
\end{array}\right],
\end{aligned}
$$

where $l_{\mathrm{sd}}$ and $l_{\mathrm{rd}}$ are the stator and rotor leakage inductances, and $m_{k}$ is given by (14).

The $a b c$ variables are transformed into the $0 \mathrm{FB}$ variables by the complex rotating transformation [T] or forward-backward transformation (abbreviated as FB-transformation) [20] expressed in the stationary reference frame 


$$
\begin{aligned}
{\left[\mathbf{x}_{\mathrm{T}}\right]=[\mathbf{T}][\mathbf{x}] \rightarrow } & {\left[\begin{array}{c}
x_{0} \\
x_{\mathrm{F}} \\
x_{\mathrm{B}}
\end{array}\right]=\frac{1}{\sqrt{3}}\left[\begin{array}{ccc}
1 & 1 & 1 \\
1 & \mathrm{a} & \mathrm{a}^{2} \\
1 & \mathrm{a}^{2} & \mathrm{a}
\end{array}\right]\left[\begin{array}{l}
x_{\mathrm{a}}(t) \\
x_{\mathrm{b}}(t) \\
x_{\mathrm{c}}(t)
\end{array}\right], } \\
& \left(\text { being }[\mathbf{T}]^{-1}=\left[\mathbf{T}^{*}\right]^{\mathrm{t}}\right)
\end{aligned}
$$

where 0 is the zero-sequence component, and $\mathrm{F}$ and $\mathrm{B}$ are the forward and backward components, which are complex conjugate. Note that matrix $[\mathbf{T}]$ in (18) is the Fortescue matrix, which is used for the symmetrical component transformation. The forward component of (18) is also known in the literature as the space vector, the spatial vector, or the space phasor of the $a b c$ phase quantities.

The electrical equations of (15) are expressed in transformed variables as

$$
\begin{aligned}
& {\left[\mathbf{v}_{\mathbf{T}}\right]=[\mathbf{R}]\left[\mathbf{i}_{\mathbf{T}}\right]+\frac{\mathrm{d}}{\mathrm{dt}}\left[\lambda_{\mathrm{T}}\right] \quad\left[\lambda_{\mathbf{T}}\right]=\left[\mathbf{M}_{\mathbf{T}}(\theta)\right]\left[\mathbf{i}_{\mathbf{T}}\right]} \\
& {\left[\mathbf{M}_{\mathbf{T}}(\theta)\right]=\left[\mathbf{T}_{\mathbf{C}}\right][\mathbf{M}(\theta)]\left[\mathbf{T}_{\mathbf{C}}\right]^{-1},}
\end{aligned}
$$

where $\left[\mathbf{T}_{\mathrm{C}}\right]$ is the complete transformation matrix

$$
\left[\mathbf{T}_{\mathbf{C}}\right]=\left[\begin{array}{ll}
\mathbf{T} & \mathbf{0} \\
\mathbf{0} & \mathbf{T}
\end{array}\right] .
$$

The electromagnetic torque expressed in transformed variables is calculated as

$$
T(t)=p \frac{1}{2}\left[\mathbf{i}_{\mathbf{T}}^{*}\right]^{t} \frac{\partial}{\partial \theta}\left\{\left[\mathbf{M}_{\mathbf{T}}(\theta)\right]\right\}\left[\mathbf{i}_{\mathbf{T}}\right] .
$$

The stator and rotor zero-sequence equations in (19) are decoupled from the remaining equations. Furthermore, the forward and backward equations of (19) are complex conjugate. Thus, machine behaviour can be expressed with the zero-sequence and forward equations only, and using the 0 and $\mathrm{F}$ variables:

$$
\begin{aligned}
& k=6 n+3 \quad(n=0,1,2 \ldots) \\
& v_{\mathrm{s} 0}=R_{\mathrm{s}} i_{\mathrm{s} 0}+\frac{\mathrm{d}}{\mathrm{dt}}\left\{\left(L_{\mathrm{sd}}+\sum_{k=3,9,15} 2 M_{k}\right) i_{\mathrm{s} 0}\right\} \\
& v_{\mathrm{r} 0}=R_{\mathrm{r}} i_{\mathrm{r} 0}+\frac{\mathrm{d}}{\mathrm{dt}}\left\{\left(L_{\mathrm{rd}}+\sum_{k=3,9,15} 2 M_{k}\right) i_{\mathrm{r} 0}\right\} \\
& \begin{array}{l}
k=6 n+1(\text { positive sign) and } k=6 n+5 \text { (negative sign) } \\
(n=0,1,2 \ldots)
\end{array} \\
& {\left[\begin{array}{l}
v_{\mathrm{sF}} \\
v_{\mathrm{rF}}
\end{array}\right]=\left[\begin{array}{cc}
R_{\mathrm{s}} & 0 \\
0 & R_{\mathrm{r}}
\end{array}\right]\left[\begin{array}{l}
i_{\mathrm{sF}} \\
i_{\mathrm{rF}}
\end{array}\right]} \\
& +\frac{\mathrm{d}}{\mathrm{dt}}\left\{\left[\begin{array}{ll}
L_{\mathrm{sd}}+\sum_{k=1,5,7} M_{k} & \sum_{k=1,5,7} M_{k} \mathrm{e}^{ \pm \mathrm{j} k \theta} \\
\sum_{k=1,5,7} M_{k} \mathrm{e}^{-( \pm \mathrm{j} k \theta)} & L_{\mathrm{rd}}+\sum_{k=1,5,7} M_{k}
\end{array}\right]\left[\begin{array}{l}
i_{\mathrm{sF}} \\
i_{\mathrm{rF}}
\end{array}\right]\right\},
\end{aligned}
$$

where the following change of variables is made:

$$
L_{\mathrm{sd}}=l_{\mathrm{sd}}, \quad L_{\mathrm{rd}}=l_{\mathrm{rd}}, \quad M=\frac{3}{2} m_{1}, \quad M_{k}=\frac{3}{2} m_{k} .
$$

In (22) the writing of the equations depends on the order of the harmonic inductances $M_{k}$ :

The zero-sequence equations only depend on the harmonic inductances of order $k=3,9,15 \ldots$ (i.e., $k=6 n+3$, where $n=0,1,2 \ldots$.). These harmonics are called zero-sequence harmonics. 
The positive sign in the forward equations is for the fundamental $(k=1)$ and harmonic inductances of order $k=7,13 \ldots$, (i.e., $k=6 n+1$, where $n=0,1,2 \ldots$ ). These harmonics are called forward harmonics as fluxes of this order travel forward (in the direction of the fundamental field) at sub-synchronous speeds of $\left(\omega_{\mathrm{s}} / p\right) / k$.

The negative sign in the forward equations is for the harmonic inductances of order $k=5,11 \ldots$ (i.e., $k=6 n+5$, where $n=0,1,2 \ldots)$. These harmonics are called backward harmonics as fluxes of this order travel backward (in the direction of the fundamental field) at sub-synchronous speeds of $\left(\omega_{\mathrm{s}} / p\right) / k$.

And the torque with only the $\mathrm{F}$ variables is

$$
\begin{aligned}
T(t) & =p \operatorname{Re}\left(\left[\begin{array}{ll}
i_{\mathrm{sF}}^{*} & i_{\mathrm{rF}}^{*}
\end{array}\right] \frac{\partial}{\partial \theta}\left\{\left[\mathbf{M}_{\mathrm{TF}}(\theta)\right]\right\}\left[\begin{array}{c}
i_{\mathrm{sF}} \\
i_{\mathrm{rF}}
\end{array}\right]\right) \\
& =p 2 \operatorname{Im}\left(i_{\mathrm{sF}} i_{\mathrm{rF}}^{*} \sum_{k=1,5,7} \pm k M_{k} \mathrm{e}^{-( \pm \mathrm{j} k \theta)}\right),
\end{aligned}
$$

where $\left[\mathbf{M}_{\mathbf{T F}}(\theta)\right]$ is composed of the F elements of matrix $\left[\mathbf{M}_{\mathbf{T}}(\theta)\right]$.

\subsection{Steady-state equivalent circuit}

The steady-state closed-form solution of the previous model is cumbersome because the spectrum of the stator and rotor currents is infinite even if only one harmonic in $M_{k}$ is considered (assuming the stator is supplied by a sinusoidal voltage source). A steady-state model with truncation of stator and rotor currents was obtained but it is not included here for brevity purposes [21].

A more useful approximate steady-state solution is found if stator windings are assumed to be supplied by a

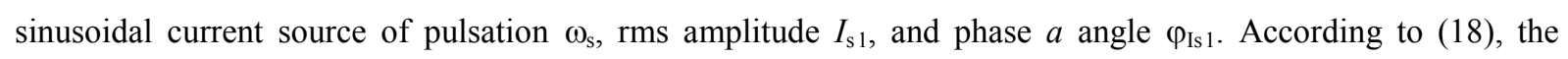
forward stator current is

$$
i_{\mathrm{sF}}=i_{\mathrm{sF} 1}=\sqrt{3 / 2} \cdot I_{\mathrm{s} 1} \mathrm{e}^{\mathrm{j}\left(\omega_{\mathrm{s}} t+\varphi_{\mathrm{Is} 1}\right)}=\sqrt{3 / 2} \cdot \underline{I}_{\mathrm{s} 1} \mathrm{e}^{\mathrm{j} \omega_{\mathrm{s}} t}
$$

where $\underline{I}_{\mathrm{s} 1}$ is the phasor of phase $a$. Let us also assume that the harmonic content of $v_{\mathrm{sF}}$ can be neglected:

$$
v_{\mathrm{sF}} \approx v_{\mathrm{sF} 1}=\sqrt{3 / 2} \cdot V_{\mathrm{s} 1} \mathrm{e}^{\mathrm{j}\left(\omega_{\mathrm{s}} t+\varphi_{\mathrm{V} 1}\right)}=\sqrt{3 / 2} \cdot \underline{\mathrm{s}}_{\mathrm{s} 1} \mathrm{e}^{\mathrm{j} \omega_{\mathrm{s}} t} .
$$

Then, the analysis of the forward stator equation in (22) indicates the frequencies in $i_{\mathrm{rF}}$. As the term $\frac{\mathrm{d}}{\mathrm{dt}}\left\{\left(L_{\mathrm{sd}}+\sum_{k=1,5,7} M_{k}\right) i_{\mathrm{sF} 1}\right\}$ pulsates at $\omega_{\mathrm{s}}$, then the term $\frac{\mathrm{d}}{\mathrm{dt}}\left\{\left(\sum_{k=1,5,7} M_{k} \mathrm{e}^{ \pm \mathrm{j} k \theta}\right) i_{\mathrm{rF}}\right\}$ also pulsates at $\omega_{\mathrm{s}}$, and the rotor current $i_{\mathrm{rF}}$ pulsates at $\left(\omega_{\mathrm{s}} t-( \pm k \theta)\right) / t$. Thus,

$$
\begin{aligned}
i_{\mathrm{rF}} & =\sum_{k=1,5,7} i_{\mathrm{rF} k}=\sum_{k=1,5,7} \sqrt{3 / 2} \cdot I_{\mathrm{r} k} \mathrm{e}^{\mathrm{j}\left(\omega_{\mathrm{s}} t-( \pm k \theta)+\varphi_{\mathrm{rr} k}\right)} \\
& =\sqrt{3 / 2} \cdot \underline{I}_{\mathrm{r} k} \mathrm{e}^{\mathrm{j}\left(\omega_{\mathrm{s}} t-( \pm k \theta)\right)} .
\end{aligned}
$$

By replacing (25), (26) and (27) in the forward equations of (22), dividing the stator equation by $\sqrt{3 / 2} \cdot \mathrm{e}^{\mathrm{j} \omega_{\mathrm{s}} t}$ and the rotor equations by $s_{k} \sqrt{3 / 2} \cdot \mathrm{e}^{\mathrm{j}\left(\omega_{\mathrm{s}} t-( \pm k \theta)\right)}$, and using that $\theta=p \omega_{\mathrm{m}} t+\theta_{0}$, the following phasor equations are obtained: 


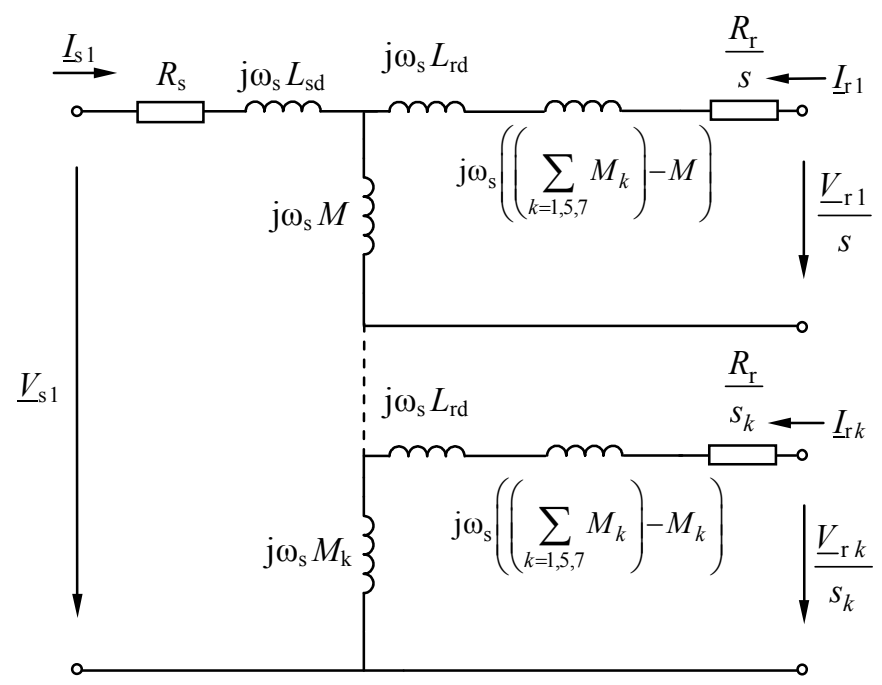

Fig. 7 Single-cage chain model for the induction machine with non-sinusoidally distributed windings, uniform air-gap and without skin effect. The model assumes that the stator is supplied by a purely sinusoidal current source.

$$
\begin{aligned}
\underline{V}_{\mathrm{s} 1}= & R_{\mathrm{s}} \underline{I}_{\mathrm{s} 1}+\mathrm{j} \omega_{\mathrm{s}} L_{\mathrm{sd}} \underline{I}_{\mathrm{s} 1}+\mathrm{j} \omega_{\mathrm{s}} \sum_{k=1,5,7}\left(M_{k}\left(\underline{I}_{\mathrm{s} 1}+\underline{I}_{\mathrm{r} k}\right)\right) \\
\frac{\underline{V_{\mathrm{r} k}}}{s_{k}}= & \frac{R_{\mathrm{r}}}{s_{k}} \underline{I}_{\mathrm{r} k}+\mathrm{j} \omega_{\mathrm{s}}\left(L_{\mathrm{rd}}+\left(\sum_{k=1,5,7} M_{k}\right)-M_{k}\right) \underline{I}_{\mathrm{r} k} \\
& +\mathrm{j} \omega_{\mathrm{s}} M_{k}\left(\underline{I}_{\mathrm{s} 1}+\underline{I}_{\mathrm{r} k}\right) \\
\text { where: } & s_{k}=\frac{\omega_{\mathrm{s}}-\left( \pm k p \omega_{\mathrm{m}}\right)}{\omega_{\mathrm{s}}}=1-( \pm k(1-s)) \\
& (k=1,5,7,11 \ldots) .
\end{aligned}
$$

These equations can be expressed with the steady-state equivalent circuit in Fig. 7, where the average torque is calculated as

$$
\begin{aligned}
T(s) & =\langle T(t)\rangle=3 p \operatorname{Im}\left\{\sum_{k=1,5,7} \pm k M_{k} \underline{I}_{\mathrm{s} 1} \underline{I}_{\mathrm{r} k}^{*}\right\} \\
& =\sum_{k=1,5,7} \pm k \frac{3 p}{\omega_{\mathrm{s}}}\left(\frac{R_{\mathrm{r}}}{s_{k}} I_{\mathrm{r} k}^{2}\right) .
\end{aligned}
$$

The circuit in Fig. 7 leads to the chain model in Fig. 5c if the following changes are made: (1) rotor windings are short-circuited (i.e., $\underline{V}_{\mathrm{r} 1}=\underline{V}_{\mathrm{r} k}=0$ ), and (2) the two leakage inductances of the rotor subcircuits are substituted by a total rotor leakage inductance (note that the inductance $\left(\sum_{k=1,5,7} M_{k}\right)-M_{k}$ can be considered a leakage inductance).

\subsection{Dynamic and steady-state model simulation}

In order to illustrate the model behaviour, the induction motor of Table 5 is simulated. The parameters of the classical single-cage model are given in this table. A $7^{\text {th }}$ space harmonic is included in the model by considering inductance $M_{7}$. The space harmonic amplitude is exaggerated to equal that of a concentrated winding (squarewave $\mathrm{mmf}$ ): $M_{7}=M / 49$. Two simulations are performed: the stator is supplied by a voltage source or by a current source. 
Table 5 Simulated induction motor parameters in pu $\left(S_{\mathrm{B}}=P_{\mathrm{N}}, U_{\mathrm{B}}=U_{\mathrm{N}}, Z_{\mathrm{B}}=U_{\mathrm{B}}{ }^{2} / S_{\mathrm{B}}\right)$

\begin{tabular}{ccccccccc}
\hline \hline$P_{\mathrm{N}}(\mathrm{kW})$ & $U_{\mathrm{N}}(\mathrm{V})$ & $f_{\mathrm{N}}(\mathrm{Hz})$ & $P F_{\mathrm{N}}$ & $\omega_{\mathrm{N}}(\mathrm{r} / \mathrm{min})$ & $\eta_{\mathrm{N}}(\%)$ & $T_{\mathrm{MAX}} / T_{\mathrm{N}}$ & $T_{\mathrm{ST}} / T_{\mathrm{N}}$ & $I_{\mathrm{ST}} / I_{\mathrm{N}}$ \\
2.2 & 400 & 50 & 0.70 & 925 & 69.8 & 2.1 & 1.1 & 2.9 \\
\hline$r_{\mathrm{s}}$ & $x_{\mathrm{sd}}=x_{\mathrm{rd}}$ & $x_{\mathrm{m}}$ & $r_{\mathrm{r}}$ & & & $7^{\text {th }}$ harmonic: $x_{\mathrm{m} 7}$ \\
0.0256 & 0.0679 & 0.5791 & 0.0379 & & $0.5791 / 49=0.0118$ \\
\hline \hline
\end{tabular}

The results are shown in Fig. 8 (solid and broken lines for the voltage and current source, respectively). The instantaneous torque and currents are obtained with the dynamic model in (22)-(24) while the steady-state torque- and current-slip curves are obtained with the steady-state model with truncation from [21] (voltage source) and the model in (28)-(29) (current source). The hypothesis of the stator supplied by a sinusoidal current source is suitable, as the differences between both cases are not significant. As expected from the exaggeration of the harmonic amplitude, the results are rather extreme, especially the large oscillations in the instantaneous torque. Thus, the model seems unable to predict the measured squirrel-cage torque irregularities in Fig. 1, Fig. 2 and Fig. 3.

Two conclusions can be extracted from this analytical model: (1) the harmonic magnitudes must be exaggerated to make their effects on the torque-speed curve visible; (2) it cannot be used directly (without changes) for motors where space harmonic and skin effects are apparent because of the various simplifying assumptions.

\section{Acknowledgements}

This research work has been supported by the Spanish Ministry of Economy and Competitiveness through project DPI2011-28021.
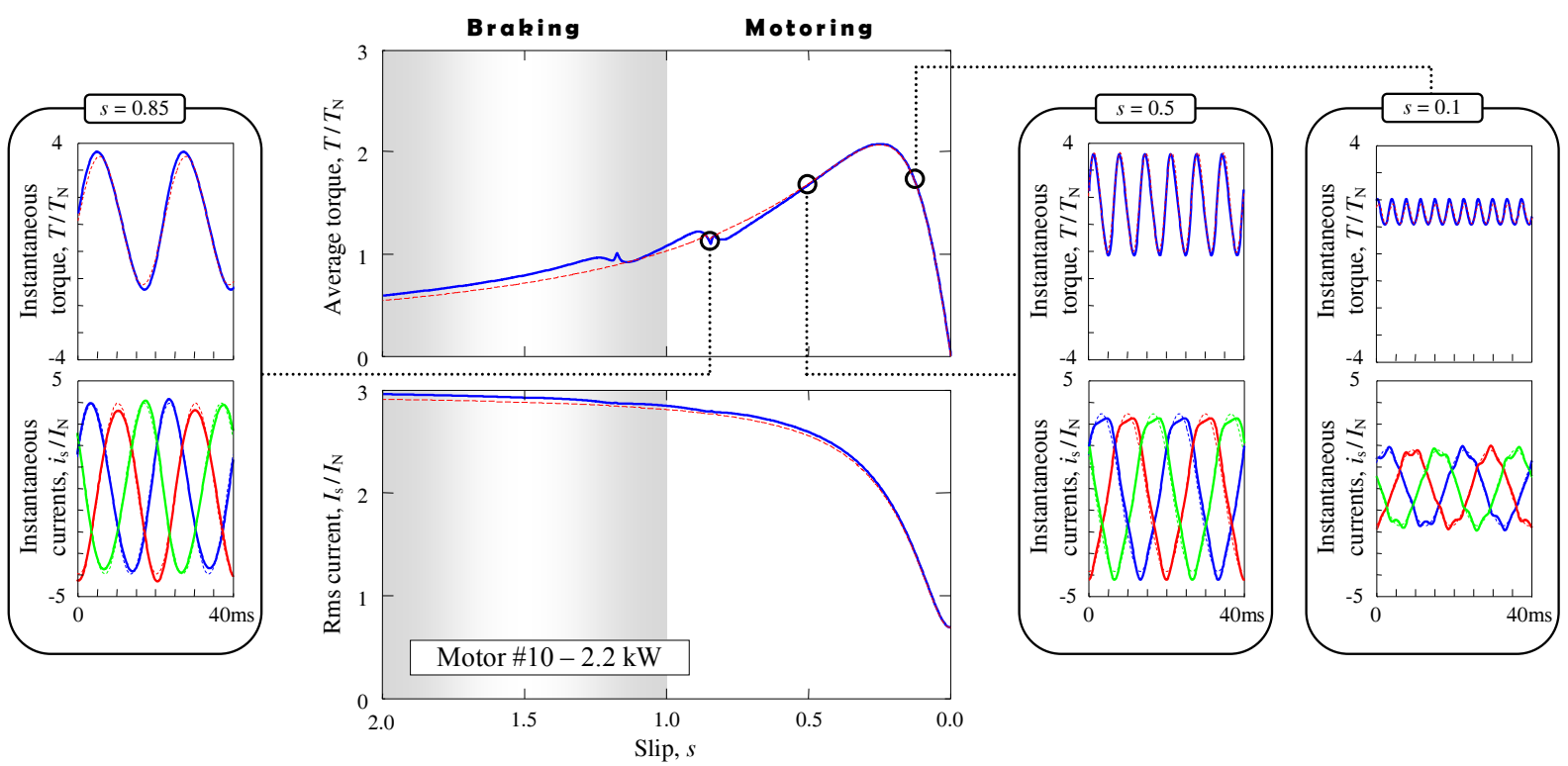

Fig. 8 Simulated (average) torque and (rms) current-slip curves for the motor of Table 5 assuming non-sinusoidally distributed windings (concentrated windings), uniform air-gap and no skin effect. The instantaneous torque and currents at three different points with slips 0.85 , 0.5 and 0.1 are also plotted. The stator is supplied by a sinusoidal voltage source (solid line) and a sinusoidal current source (broken line). 


\section{References}

1 Boldea, I. and Nasar, S. A., The Induction Machine Handbook. 2nd ed. Boca Raton, FL: CRC Press, 2010, pp. 273-286.

2 Hamdi, E. S., Design of Small Electrical Machines. Chichester, England: John Wiley \& Sons, 1994, pp. 128-133, 185228.

3 ABB Oy/Drives, Drive Size v3.8, 2013. Available (3 Apr. 2014): http://www.abb.com

4 European Commission, EuroDEEM International v. 1.0.17, 2007. Available (3 Apr. 2014): http://www.sunbird.jrc.it/energyefficiency/eurodeem

5 Agarwal, P.D.: 'Equivalent circuits and performance calculations of canned motors,' IEEE Trans. on PAS, Part III, 1960, 79 (3), pp. 635-642, Oct. 1960.

6 Christofides, N.: 'Origins of load losses in induction motors with cast aluminium rotors,' Proc. of the IEE, 1965, 112, (12), pp. 2317-2332.

7 Subba, V. and Butler, O. I.: 'Stray losses of polyphase cage-induction motors with particular reference to the condition of imperfect rotor-bar-iron insulation,' Proc. of the IEE, 1969, 116, (5), pp. 737-751.

8 Kron, G.: 'Induction motor slot combinations. Rules to predetermine crawling, vibration, noise and hooks in the speedtorque curve,' Trans. of the AIEE, 1931, 50, (2), pp. 757-767.

9 Heartz, R. A. and Saunders, R. M.: 'Harmonics due to slots in electric machines,' IEEE Trans. on PAS, Part III, 1954, 73, (2), pp. 946-949.

10 Robinson, R. B.: 'Inductance coefficients of rotating machines expressed in terms of winding space harmonics,' Proc. of the IEE, 1964, 111, (4), pp. 769-774.

11 Barton, T.H., and Dunfield, J. C.: 'Inductances of a practical slip-ring primitive. I - An analytical study,' IEEE Trans. on $P A S, 1966,85,(2)$, pp. 140-145.

12 Lesenne, J. Notelet, F. and Seguier, G. 'Introduction a l'Electrotechnique Approfondie'. Paris: Technique \& Documentation, 1981, pp. 33-39.

13 Fudeh, H.R. and Ong, C. M. 'Modeling and analysis of induction machines containing space harmonics. Parts I, II and III,' IEEE Trans. on PAS, 1983, 102, (8), pp. 2608-2628.

14 Echevarría-Villar, J.-A. Martinez-Román, J. and Serrano-Iribarnegaray, L.: 'Transient harmonic torques in induction machines: measurement and impact on motor performance,' Electrical Engineering, 2012, 94, (2), pp. 67-80.

15 Pedra, J., Córcoles, F., Monjo, Ll., Bogarra, S., and Rolán, A.: 'On fixed speed WT generator modeling for rotor speed stability studies,' IEEE Trans. Power Syst., 2012, 27, (1), pp. 397-406.

16 Odok, A. M.: 'Stray-load losses and stray torques in induction machines,' IEEE Trans. on PAS, Part III, 1958, 77, (3), pp. 43-53.

17 Monjo, Ll., Córcoles, F., and Pedra, J.: 'Saturation effects on torque- and current-slip curves of squirrel-cage induction motors,' IEEE Trans. Energy Conv., 2013, 28, (2), pp. 243-254.

18 Pedra, J., and Córcoles, F.: 'Estimation of induction motor double-cage model parameters from manufacturer data,' IEEE Trans. Energy Conv., 19, (2), pp. 310-317.

19 The MathWorks, Inc., Matlab 7.9 (R2009b). Natick, MA: 2009.

$20 \mathrm{Ku}, \mathrm{Y}$. H.: 'Rotating-field theory and general analysis of synchronous and induction machines,' Proc. IEE - Part IV: Institution Monographs, 1952, 99, (4), pp. 410-428.

21 Monjo, L1, “Aportacions a la modelització de la màquina d'inducció de gàbia d'esquirol” PhD Dissertation, Jul. 2013 (in Catalan): http://www.tdx.cat/handle/10803/129457 